\title{
Organization and recognition accuracy: The effect of context on blocked presentation
}

\author{
ROBERT M. SCHWARTZ \\ Stanford University, Stanford, California 94305
}

\begin{abstract}
The effect of blocking related items at presentation on recognition memory was examined. When individual words were presented, blocking was found to facilitate recognition accurracy, but no facilitation was found when the words were presented in sentences which included the category name. The results were discussed in terms of the confounding of organizational effects and context effects.
\end{abstract}

Recent research has failed to demonstrate clearly whether organization affects recognition accuracy (cf. Bruce \& Fagan, 1970; Jacoby, 1972). Schwartz and Humphreys (1974) have argued that this failure may be due to a confounding of organizational manipulations with the context of items in the to-be-remembered list. That is, in some experiments, subjects in high-organization and low-organization conditions have not been presented the same lists in the same orders. To avoid this confounding, Schwartz and Humphreys presented subjects the same lists in the same orders, but they gave their subjects differential instructions about processing the list items. In two experiments, they found no effect of their instructions on recognition accuracy.

The present experiment was conducted to elucidate further the nature of the confounding of organization and context. To do this, a manipulation which has been found to affect recognition accuracy was examined. This manipulation is whether items from the same category are blocked at presentation or whether they are spaced at presentation. Blocking items from the same category has been shown to facilitate recognition accuracy (Jacoby, 1972; D’Agostino, 1969).

The blocking effect may be due to two sources. First, blocking may lead to higher organization which, in turn, affects recognition accuracy. Alternatively, blocked presentation provides a different presentation context for each to-be-remembered item than does spaced presentation, and different contexts may be responsible for the blocking effect. For example, presenting orange adjacently to yellow should lead the subject to encode orange as a color; however, if orange is presented adjacently to deer, he may encode orange as a fruit. That context can create differential encoding and that differential encoding can affect recognition accuracy has been clearly demonstrated (e.g., Light \& Carter-Sobell, 1970).

In order to eliminate differential encoding in the present experiment, some subjects in both blocked and

This research was conducted during the author's tenure as an NIMH postdoctoral trainee. This paper is sponsored by Michael S. Humphreys, who takes full editorial responsibility for it Robert M. Schwartz's current address is Department of Psychology, Rio Hondo College, Whittier, California 90608. spaced conditions were required to encode in the same manner. This was accomplished by embedding the to-be-remembered items in sentences which included the category names. An example sentence is: Orange is a fruit. For the other subjects in both blocked and spaced conditions, items were not embedded in sentences. If the organizational hypothesis is correct, it would be predicted that blocking would facilitate recognition accuracy regardless of whether the items are embedded in sentences. If the context alternative is correct, it would be predicted that blocking would facilitate recognition accuracy only when the items are not embedded in sentences.

\section{METHOD}

\section{Stimuli and materials}

The stimuli were 10 associates to each of 25 categories in the Battig and Montague (1969) and Shapiro and Palermo (1969) norms. Two words from each category were chosen to be on the to-be-remembered list. The remaining eight words from each category served as distractors for the recognition test.

The 25 categories were randomly arranged for presentation. For the blocked conditions, the two to-be-remembered words from each category were presented adjacently in this arrangement. For the spaced conditions, the first 25 to-be-remembered words were the odd numbered words in the blocked conditions' presentation order; the next 25 to-be-remembered words were the even numbered words in the blocked conditions' presentation order. Thus, in the spaced conditions, the two words from a given category were separated.

The stimuli were typed on $3 \times 5$ in. cards, with one item on each card. For the word conditions, only the to-be-remembered words appeared on the cards. For the sentence conditions, each word was embedded in a sentence which included the category name, e.g., Orange is a color. The to-be-remembered word was underlined.

For the recognition answer booklets, the 50 to-be-remembered words were randomly arranged for testing. One of these words was included on each of 25 lines on each of two answer sheets. Four words from the same category as each to-be-remembered word appeared on the same line as that word. The placement of the to-be-remembered word in the five resulting columns was randomly determined.

\section{Design}

A 2 by 2 factorial design, with both factors varying between groups of subjects was used. The first factor was whether the subject was given blocked or spaced presentation, and the second 
factor was whether he was presented words or sentences. The four resulting conditions were labeled blocked-word, spaced-word, blocked-sentence, and spaced-sentence.

Two other factors were varied between groups of subjects, but, as these were varied only to provide for generality of results, they were not included in the analysis. First, order of presentation was varied. The first 40 subjects who participated in the experiment were presented the lists in the orders described previously; the remaining 40 subjects were presented the lists in the reverse orders. Second, the two pages of the answer booklets were reversed for both the second 20 and final 20 subjects who participated in the experiment.

\section{Subjects}

The subjects were 80 volunteers from introductory psychology classes at Stanford University, and they participated in partial fulfillment of a course requirement. The subjects were seen individually, and they were assigned to conditions randomly, with the restriction that one of the first four subjects served in each of the four conditions, etc.

\section{Procedure}

The subjects were told that they would be presented 50 words, one at a time, and that they would be tested for their memory of these words. They were not informed of the nature of the test. The subjects in the sentence conditions were told that the to-be-remembered words were embedded in sentences and that the to-be-remembered word in each sentence was underlined. All subjects were required to read aloud once the content, either a word or a sentence, of each card they were presented. After they finished reading aloud and before the experimenter presented the next card, the subjects were to study covertly in any manner that they desired.

The list was presented at a rate of $4.5 \mathrm{sec}$ per item. The click of a battery-operated timer paced the experimenter's presentation. Immediately following presentation, the subjects were handed recognition answer bookelts. The first page of each booklet contained instructions. These informed the subjects that there were five words on each line and that one, and only one, of these had been on the list they were presented. They were to circle that word. If they did not know which word had been presented, they were instructed to guess. The instructions also informed the subjects that there were two answer sheets; they were to complete the first sheet before attempting the second sheet. The subjects were not allowed to return to the first sheet after they began to work on the second sheet.

\section{RESULTS AND DISCUSSION}

The score for each subject was the number of recognition errors; an omission was counted as .8 errors. Means for these scores were $2.19,4.97,5.19$, and 6.04 for the blocked-word, spaced-word, blocked-sentence, and spaced-sentence conditions, respectively.

Each subject's score was transformed using a $\sqrt{x+.5}$ transformation, and the transformed data were subjected to analysis of variance. The results of the analysis indicate that presenting words in sentences produced significantly decreased recognition accuracy $[\mathrm{F}(1,76)=$ $4.96, \mathrm{p}<.05]$. For the word conditions, blocking resulted in significantly increased recognition accuracy $[F(1,76)=6.86, p<.02]$. However, for the sentence conditions, blocking did not result in significantly increased recognition accuracy, $\mathrm{F}<1$.

The data from the present experiment clearly suggest that if the differential encoding caused by blocking related items at presentation is removed, blocking does not result in increased recognition accuracy. Thus, earlier research on the effects of blocking on recognition may have been more relevant to the effects of context than to the effects of increased organization. It is tempting to extend the present argument to other manipulations of organization which have varied context along with degree of organization. However, a safer conclusion is that in testing the effects of organization, it is best to present subjects the same lists in the same orders. In two experiments which met this requirement, Schwartz and Humphreys (1974) found no effect of organization on recognition accuracy when instructional manipulations were used.

\section{REFERENCES}

Battig, W. F., \& Montague, W. E. Category norms for verbal items in 56 categories: A replication and extension of the Connecticut category norms. Journal of Experimental Psychology, 1969, 80, (3, Pt. 2).

Bruce, D., \& Fagan, R. L. More on recognition and free recall of organized lists. Journal of Experimental Psychology, 1970, 85, 153-154.

D'Agostino, P. R. The blocked-random effect in recall and recognition. Journal of Verbal Learning and Verbal Behavior, $1969,8,858-866$.

Jocoby, L. J. Effects of organization on recognition memory. Journal of Experimental Psychology, 1972, 92, 325-331.

Light, L. L., \& Carter-Sobell, L. Effects of changed semantic context on recognition memory. Journal of Verbal Learning and Verbal Behavior, 1970, 9, 1-11.

Schwartz, R. M., \& Humphreys, M. S. Recognition and recall as a function of instructional manipulations of organization. Journal of Experimental Psy chology, 1974, 102, 517-519.

Shapiro, S. I., \& Palermo, D. S. Conceptual organization and class membership: Normative data for representatives of 100 categories. Psychonomic Monograph Supplements, 1969, 11, (Whole No. 43).

(Received for publication January 3, 1975.) 